\title{
Characterization of winged bean (Psophocarpus tetragonolobus (L.) DC.) based on molecular, chemical and physiological parameters
}

\author{
Chandra Sekhar Mohanty ${ }^{1}$, Sushma Verma ${ }^{1}$, Vinayak Singh ${ }^{1}$, Shahina Khan ${ }^{1}$, Priyanka Gaur ${ }^{2}$, \\ Priya Gupta ${ }^{1}$, M. Abdul Nizar ${ }^{3}$, Nilamani Dikshit ${ }^{3}$, Rojalin Pattanayak $^{4}$, Alpika Shukla ${ }^{4}$, \\ Abhishekh Niranjan ${ }^{1}$, Nayan Sahu ${ }^{1}$, Soumit Kumar Behera ${ }^{1}$, Tikam Singh Rana ${ }^{1}$ \\ ${ }^{1}$ CSIR-National Botanical Research Institute, Rana Pratap Marg, Lucknow, Uttar Pradesh, India \\ ${ }^{2}$ Sanjay Gandhi Institute of Post-Graduate Medical Sciences, Lucknow, Uttar Pradesh, India \\ ${ }^{3}$ National Bureau of Plant Genetic Resources, Regional Station, Akola, Maharashtra, India \\ ${ }^{4}$ University of Lucknow, Lucknow, Uttar Pradesh, India \\ Email: ${ }^{*}$ cs.mohanti@nbri.res.in, ${ }^{*}$ sekhar_cm2002@,rediffmail.com
}

Received 9 July 2013; revised 11 August 2013; accepted 6 September 2013

Copyright (C) 2013 Chandra Sekhar Mohanty et al. This is an open access article distributed under the Creative Commons Attribution License, which permits unrestricted use, distribution, and reproduction in any medium, provided the original work is properly cited.

\begin{abstract}
Winged bean (Psophocarpus tetragonolobus (L.) DC.) is a potential legume crop of the tropics with high protein and oil content in the seeds. Analysis of the mutual genotypic relationships among twenty four genotypes of $P$. tetragonolobus through Mantel test found a significant correlation $(r=0.839)$ between similarity matrices of the results obtained from the use of the RAPD and ISSR molecular markers. The UPGMA tree based on Jaccard's similarity coefficient generated from their cumulative data showed two distinct clusters and seven sub-clusters among these accessions. Quantification of total polyphenols, flavonoids and tannin revealed the highest percentage of occurrence of kaempferol $(1.07-790.5 \mu \mathrm{g} / \mathrm{g})$ and the lowest percentage of gallic acid $(0.09-3.49 \mu \mathrm{g} / \mathrm{g})$ in the seeds. Phytochemical analysis of the winged bean genotypes revealed that, some of the exotic lines are distinct. Analysis of photosynthesis rate, photosynthetic yield and stomatal conductance data also showed two clusters and was in congruence with the phytochemical affinities of the genotypes. The overall high level of polymorphism and varied range of genetic distances across the genotypes revealed a wide range of genetic base of $P$. tetragonolobus. The present investigation therefore, has provided significant insights for further improvement of winged bean germplasm for its qualitative and quantitative traits.
\end{abstract}

Keywords: Psophocarpus tetragonolobus; Polyphenols;

"Corresponding author.
Flavonoid; RAPD; ISSR; Physiological Parameter

\section{INTRODUCTION}

Psophocarpus tetragonolobus (L.) DC. (Fam. Fabaceae) popularly known as Winged bean or Goa bean is a tropical legume found growing abundantly in hot, humid equatorial countries, like India, Burma, Sri Lanka, Thailand and Philippines. It is also called a wonder legume as it has the high protein content in the seeds and therefore considered as a versatile legume [1]. It is a diploid $(2 n=$ $2 x=18$ ), self-fertilizing leguminous crop with multifarious usage [2]. It can be grown as a grain legume, green vegetable, tuber-crop or a forage and cover-crop [3]. Seeds of winged bean contain some pharmacologically active anti-nutrients such as trypsin and chymotrypsin inhibitors [4], haematoglutins and amylase inhibitors. There are other unfavorable compounds like tannins (proanthocyanidins), which have been reported to be present in the seeds of winged bean [5]. Tannins are polyphenolic compounds and are either hydrolysable or condensed. It can interact and precipitate with protein and therefore, reduce food protein quality in monogastrics [6]. Knowledge of genetic diversity within and among genotypes of any crop is fundamental to estimate the potential of genetic gain in breeding programs and for effective conservation and sustainable utilization of available genetic resources [7]. All food legumes are valuable sources of proteins, vitamins and minerals and occupy an important place in human nutrition. Assessment of genetic variations and relationships among these leguminous crops may therefore, play a significant role 
in breeding programs to improve grain yield, oil and protein content. Winged bean is of rapidly increasing interest as a high-protein multipurpose crop. The breeding of winged bean as a grain legume requires the development of an improved ideotype with the highest nutritional content and lowest anti-nutritional factors [8].

Over the years, the methods for detecting and assessing genetic diversity have extended from analysis of discrete morphological traits to advanced biochemical and molecular traits. Several DNA based molecular markers are now currently used in diversity study of plants. Amongst them RAPD and ISSR-PCR are commonly used markers to characterize the genetic diversity of crop plants and can be immensely helpful in identifying the potential elite genotypes. The utility of these markers as a potential tool for documenting the genetic variations in several legume crops like Chickpea [9-11]. Lens [12], Lentil [13], Groundnut [14], Cajanas cajan [15], Cluster bean [16], Mung bean and Black gram [17] etc., have been clearly established over the period of time. However, no such reports on genetic diversity assessment studies using molecular markers separately or in combination with other biochemical markers are available in winged bean. The efficiency of assessment of genetic diversity to be used in breeding programme will be improved if combined biochemical and molecular data are used $[18,19]$. Thus, in the present study, RAPD and ISSR markers were used to evaluate the extent of genetic diversity amongst 24 winged bean genotypes and their efficiency in analyzing the genetic variations was compared. Furthermore, total phenolic as well as flavonoid contents along with their physiological responses to various conditions were enumerated. The use the biochemical and molecular markers will lead to select the lines with high-levels of specific polyphenol and flavonoid contents and suitable physiological performances along with genetic variability. There exists a considerable scope for incorporating promising winged bean genotypes in conventional breeding program. Apart from identifying the genetically diverse lines, attempts have been made to physiologically and biochemically characterize these plants and to establish effective correlation among these attributes.

\section{MATERIALS AND METHODS}

\subsection{Plant Material}

The plant material was procured from National Bureau of Plant Genetic Resources (NBPGR), Akola (Maharashtra), India that included genotypes from India, Thailand and Nigeria. A total of 24 winged bean genotypes along with Vigna radiata as an out-group were analyzed in the present study. The details of plant materials are given in (Table 1). The collected germplasm is now maintained in the Botanic Garden of CSIR-National Botanical Re-
Table 1. List of genotypes of $P$. tetragonolobus L. (DC.) used in the present study with their morphometric characters.

\begin{tabular}{|c|c|c|c|c|c|}
\hline S. No. & $\begin{array}{c}\text { NBPGR } \\
\text { Accession } \\
\text { Number }\end{array}$ & $\begin{array}{c}\text { NBRI } \\
\text { accession } \\
\text { code }\end{array}$ & Country & Seed Colour & $\begin{array}{c}\text { Shape of } \\
\text { Seed }\end{array}$ \\
\hline 1 & IC 95232 & Pt1 & India & Brown & Spherical \\
\hline 2 & IC 95233 & Pt2 & India & Light Brown & Spherical \\
\hline 3 & IC 95234 & Pt3 & India & Dark Brown & Round \\
\hline 4 & IC 95235 & Pt4 & India & Light Brown & Spherical \\
\hline 5 & IC 95236 & Pt5 & India & Light Brown & Round \\
\hline 6 & IC 95237 & Pt6 & India & Light Brown & Spherical \\
\hline 7 & IC 95241 & Pt7 & India & Red Brown & Spherical \\
\hline 8 & IC 95242 & Pt8 & India & Light Brown & Spherical \\
\hline 9 & IC 112416 & Pt9 & India & Dark Brown & Spherical \\
\hline 10 & EC 142660 & Pt10 & N.A. & Light Brown & Spher \\
\hline 11 & EC 142661 & Pt11 & N.A. & Light Brown & Round \\
\hline 12 & EC 142665 & Pt12 & N.A. & Light Brown & Spherical \\
\hline 13 & EC 142667 & Pt13 & Nigeria & Dark Cream & Spherical \\
\hline 14 & EC 178267 & Pt14 & Thailand & Light Brown & Spherical \\
\hline 15 & EC 178268 & Pt15 & Thailand & Light Brown & Spherical \\
\hline 16 & EC 178274 & Pt16 & Thailand & Dark Brown & Spher \\
\hline 17 & EC 178279 & Pt17 & Thailand & Dark Brown & Spherical \\
\hline 18 & EC 178283 & Pt18 & Thailand & Light Brown & Spherical \\
\hline 19 & EC 178291 & Pt19 & Thailand & Dark Brown & Wrinkled \\
\hline 20 & EC 178292 & Pt20 & Thailand & Dark Brown & Spherical \\
\hline 21 & EC 178293 & Pt21 & Thailand & Dark Brown & Spherical \\
\hline 22 & EC 178296 & Pt22 & Thailand & Light Brown & Spherical \\
\hline 23 & EC 178333 & Pt23 & Thailand & Light Brown & Round \\
\hline 24 & EC 178334 & Pt24 & Thailand & Dark Brown & Spherical \\
\hline
\end{tabular}

search Institute, Lucknow, India for further studies.

\subsection{Genomic DNA Extraction}

Total genomic DNA was isolated from the fresh leaves using DNeasy Plant Mini Kit (Qiagen, USA), according to the manufacturer's protocol. Yield and purity of genomic DNA was estimated at $\mathrm{OD}_{260 / 280}$ on spectrophotometer the integrity of genomic DNA was determined by running the DNA on $0.8 \%$ agarose gel.

\subsection{RAPD and ISSR-PCR Amplification}

A total of 13 random primers (Operon Technologies, USA), that resulted in discrete, well-separated fragments on agarose gel were selected for further amplification of entire set of the winged bean genotypes. All RAPD reactions were carried out in $25 \mu \mathrm{l}$ volume containing $50 \mathrm{ng}$ 
template DNA, 10 pm primer, $200 \mu \mathrm{m}$ each dNTPs, 2.5 $\mathrm{mM} \mathrm{MgCl}{ }_{2}$ ion concentration in suitable $1 \mathrm{X}$ buffer and 0.5 unit of the thermostable Taq DNA polymerase (Bangalore Genei, India). DNA amplification was performed in a thermal cycler (PTC 200, MJ Research Inc., USA), programmed to include pre denaturation at $94^{\circ} \mathrm{C}$ for 1 min, followed by 45 cycles of denaturation at $94^{\circ} \mathrm{C}$ for 1 min, annealing at $35^{\circ} \mathrm{C}$ for $1 \mathrm{~min}$ and extension at $72^{\circ} \mathrm{C}$ for $1 \mathrm{~min}$, the final cycle allowed an additional $5 \mathrm{~min}$ period of extension at $72^{\circ} \mathrm{C}$.

A total of 7,16 - 18 mer anchored microsatellite primers from (University of British Columbia Canada) UBC set were selected and used for ISSR analysis (Table 2). PCR amplifications were performed in a volume of $25 \mu \mathrm{l}$ containing $50 \mathrm{ng}$ of template DNA, $10 \mathrm{pm}$ primer, 200 $\mu \mathrm{m}$ each dNTPs, $2.5 \mathrm{mM} \mathrm{MgCl}$ ion concentration in suitable $1 \mathrm{X}$ buffer and 0.5 unit of the thermostable Taq DNA polymerase enzyme (Bangalore Genei, India). The thermal-cycler was programmed with an initial denaturation for $5 \mathrm{~min}$ at $94^{\circ} \mathrm{C}$, followed by 44 cycles of denatu- ration at $94^{\circ} \mathrm{C}$ for $1 \mathrm{~min}$, annealing at $55^{\circ} \mathrm{C}$ for $45 \mathrm{sec}$ and extension at $72^{\circ} \mathrm{C}$ for $1 \mathrm{~min}$ followed by $7 \mathrm{~min}$ of extension at $72^{\circ} \mathrm{C}$.

\subsection{Gel Electrophoresis}

The amplified products were electrophoresed on $1.5 \%$ agarose gels containing $0.5 \mathrm{X}$ TBE buffer stained with 0.5 $\mu \mathrm{g} / \mathrm{ml}$ ethidium bromide. The PCR product was electrophoresed at $72 \mathrm{~V}$ for $2 \mathrm{hrs}$. Low range DNA ruler of known molecular weight was used for comparing the band size of amplified products. After electrophoresis the gel was visualized in a trans-illuminator using gel documentation system (UV Tech, UK).

\subsection{Data Analysis}

The amplified bands from each DNA accession were transformed into a binary character matrix where the presence of band on a gel is scored as " 1 " and the absence of band as " 0 ". The resulting data obtained by

Table 2. RAPD and ISSR primers used to analyze the genetic diversity in Psophocarpus tetragonolobus genotypes.

\begin{tabular}{|c|c|c|c|c|c|c|}
\hline Primers & Sequence $5^{\prime}-3$ ' & Loci amplified & Polymorphic loci & Percentage polymorphism & PIC & Approx. band size range (bp) \\
\hline OPH 04 & GGAAGTCGCC & 7 & 3 & 42.8 & 0.124 & $250-2500$ \\
\hline OPH 06 & ACGCATCGCA & 6 & 6 & 100 & 0.347 & $400-2000$ \\
\hline OPH 09 & TGTAGCTGGG & 7 & 5 & 71.4 & 0.169 & $300-2000$ \\
\hline OPH 14 & ACCAGGTTGG & 7 & 7 & 100 & 0.202 & $400-1500$ \\
\hline OPH 15 & AATGGCGCAG & 6 & 3 & 50 & 0.190 & $200-2000$ \\
\hline OPM 07 & CCGTGACTCA & 9 & 8 & 88.8 & 0.149 & $400-3000$ \\
\hline OPM 10 & TCTGGCGCAC & 6 & 3 & 50 & 0.161 & $400-3000$ \\
\hline OPM 11 & GTCCACTGTG & 5 & 3 & 60 & 0.154 & $200-2500$ \\
\hline OPM 14 & AGGGTCGTTC & 3 & 1 & 33.3 & 0.110 & $500-1000$ \\
\hline OPN 08 & ACCTCAGCTC & 6 & 2 & 33.3 & 0.091 & $300-3000$ \\
\hline OPN 09 & TGCCGGCTTG & 5 & 3 & 60 & 0.077 & $280-1500$ \\
\hline OPU 03 & CTATGCCGAC & 4 & 3 & 75 & 0.234 & $300-3000$ \\
\hline \multirow[t]{2}{*}{ OPU 10} & ACCTCGGCAC & 5 & 5 & 100 & 0.299 & $400-2000$ \\
\hline & & 76 & 52 & 68.4 & $0.170^{\mathrm{av}}$ & $250-3000$ \\
\hline UBC 810 & $(\mathrm{GA})_{8} \mathrm{~T}$ & 15 & 14 & 93.3 & 0.310 & $300-2000$ \\
\hline UBC 811 & $(\mathrm{GA})_{8} \mathrm{C}$ & 15 & 14 & 93.3 & 0.203 & $500-2500$ \\
\hline UBC 825 & $(\mathrm{AC})_{8} \mathrm{~T}$ & 12 & 11 & 91.6 & 0.250 & $400-3000$ \\
\hline UBC 827 & $(\mathrm{AC})_{8} \mathrm{G}$ & 16 & 15 & 93.7 & 0.354 & $400-3000$ \\
\hline UBC 840 & $(\mathrm{GA})_{8} \mathrm{YT}$ & 06 & 05 & 83.3 & 0.225 & $300-2000$ \\
\hline UBC 841 & $(\mathrm{GA})_{8} \mathrm{YC}$ & 14 & 14 & 100 & 0.335 & $350-1900$ \\
\hline \multirow[t]{3}{*}{ UBC 855} & $(\mathrm{AC})_{8} \mathrm{YT}$ & 13 & 13 & 100 & 0.291 & $400-3000$ \\
\hline & & 91 & 86 & 94.5 & $0.281^{\mathrm{av}}$ & $300-3000$ \\
\hline & & 167 & 138 & 82.63 & $0.213^{\mathrm{av}}$ & \\
\hline
\end{tabular}

av = Average. 
scoring the RAPD and ISSR profiles with selected primers were used individually as well as cumulatively to construct a pair-wise matrix of similarities between accessions using Jaccard's coefficient [20] for unweighted pair group method with arithmetic averages, whereas the distances were computed by using Jaccard's coefficient for NJ method in the FREE TREE program ver. 0.9.1.5 [21]. The pair-wise similarity data were used to generate a UPGMA (Unweighted Pair Group Method with Arithmetic Means) tree after allowing a 1000 replicate bootstrap test using the same program. The tree was viewed, annotated and printed using TREEVIEW ver. 1.6.5. The data were further used to calculate different genetic diversity parameters such as total number of bands per primer, polymorphic bands, genetic distances and polymorphic information content (PIC). Diversity index (DI) and marker index (MI) [22] was calculated to determine the utility of the two marker systems used in the present study. Mantel test [23] was carried out in MXCOM module of NTSYS pc software ver. 2.01e [24] to compute the matrix correlation $(r)$ between the similarity matrices generated from different assays to test the goodness of fit between RAPD and ISSR markers used in the present study.

\subsection{Estimation of Biochemical Characters}

\section{Total Polyphenols}

The finely powdered plant material $(\sim 25 \mathrm{mg})$ was extracted overnight with $50 \%$ methanol: water $(3 \times 10 \mathrm{ml})$. The combined extracts were centrifuged at $6000 \times g$ for $10 \mathrm{~min}$, filtered and maintained at $30 \mathrm{ml}$. The total phenolics content (TPC) in the extract was measured by using method of Ragazzi and Veronese [25] In $0.5 \mathrm{ml}$ extract, $0.5 \mathrm{ml}$ Folins reagent $(1 \mathrm{~N})$ and $1 \mathrm{ml}$ of sodium carbonate $(20 \%)$ were subsequently added. The test mixture was mixed properly on a cyclomixer, left at room temperature for $30 \mathrm{~min}$ and maintained at $12.5 \mathrm{ml}$ with water. The absorbance of test mixture was measured at $\lambda \max 720 \mathrm{~nm}$ on a Varian Cary 50 spectrophotometer.

Further analysis of individual polyphenolic compounds were performed through HPLC-UV (Shimadzu LC-10A, Japan) equipped with dual pump LC-10AT binary system, UV detector SPD-10A at $254 \mathrm{~nm}$, rheodyne injection valve furnished with a $20 \mu$ loop on phenomenex Luna RP-C 18 column $(4.6 \times 250 \mathrm{~mm}$, i.d., $5 \mu \mathrm{m}$ pore size) preceded with guard column of same chemistry. Data was integrated by Shimadzu class VP series software. HPLC analysis of the dried powered seeds was used to generate metabolic profiles [26]. For the purpose of our analysis we selected only major metabolic peaks that showed identical retention times and uniform UV spectra in samples. Separation followed by qualitative and quantitative analysis of naturally occurring phenolics like: gallic, protocatechuic, chlorogenic, caffeic, ferulic acid and some plant flavonols like: rutin, quercetin and kaempferol were carried out (Figure 1). The correlation study among these polyphenols and flavonoid contents were analyzed through hierarchical cluster software SPSS ver. 16.0 and SAS ver. 9.2. This procedure attempted to identify the relatively homogenous groups on the basis of their chemical constituents (Figure 2). Principal component analysis was used to summarize these data.

\subsection{Estimation of Physiological Characters}

\subsubsection{Light Response}

Photosynthetic light responses to photosynthetic photon flux density (PPFD) were measured with Li-Cor 6400 XT portable photosynthesis system using artificial LED light source (Li-Cor 6400-02B). Leaf gas exchange measurements were made between 08:00 a.m. and 12:00 p.m. on the abaxial surface of leaves of all the genotypes of $P$. tetragonolobus. Six replicates of each genotype were measured for each physiological attributes. The leaf area under measurement was $2 \mathrm{~cm}^{2}$. The air flow rate, relative humidity, air temperature ( $\mathrm{T}$ air), vapour pressure deficit (VPD) and reference $\mathrm{CO}_{2}$ concentration was kept constant for all the genotypes at $500 \mu \mathrm{mols}^{-1}, 55 \%-65 \%$, $28^{\circ} \mathrm{C}, 1.5 \mathrm{KPa}$ and $400 \mu \mathrm{mol} \cdot \mathrm{m}^{-2} \cdot \mathrm{sec}^{-1}$, respectively. The light response was measured at a constant saturating PPFD of $1200 \mu \mathrm{mol} \cdot \mathrm{m}^{-2} \cdot \mathrm{sec}^{-1}$. The leaves were dark adapted by using dark adapting clips (Li-Cor 9964-091) 20 minutes prior to beginning of each measurement.

\subsubsection{Chlorophyll Fluorescence}

Leaf chlorophyll fluorescence was measured on intact, fully expanded leaves of $P$. tetragonolobus with Li-Cor 6400 XT portable photosynthesis system using artificial LED light source (Li-Cor 6400-02B). Five leaves were measured per genotype and average fluorescence value was obtained. Leaves were dark acclimated for $20 \mathrm{~min}-$ ute before measurement of maximum quantum efficiency of the photosystem II (Fv/Fm). Later, Fv'/Fm' (light harvesting efficiency by oxidized PS II reaction centers in light) was measured at saturating PPFD of 1200 $\mu \mathrm{mol} \cdot \mathrm{m}^{-2} \cdot \mathrm{sec}^{-1}$. All the statistical analysis including the cluster diagram for the physiological attributes were carried out by Systat 13.0 (Systat Software Inc., Chicago, IL).

\section{RESULTS}

\subsection{RAPD Analysis}

A total of thirteen decamer primers were used for RAPD profiling of 24 genotypes of $P$. tetragonolobus. Representative gel image for primer OPH-04 is shown in (Figure 3(a)). The sizes of the amplified products ranged from 250 - $3000 \mathrm{bp}$. These thirteen primers amplified a 

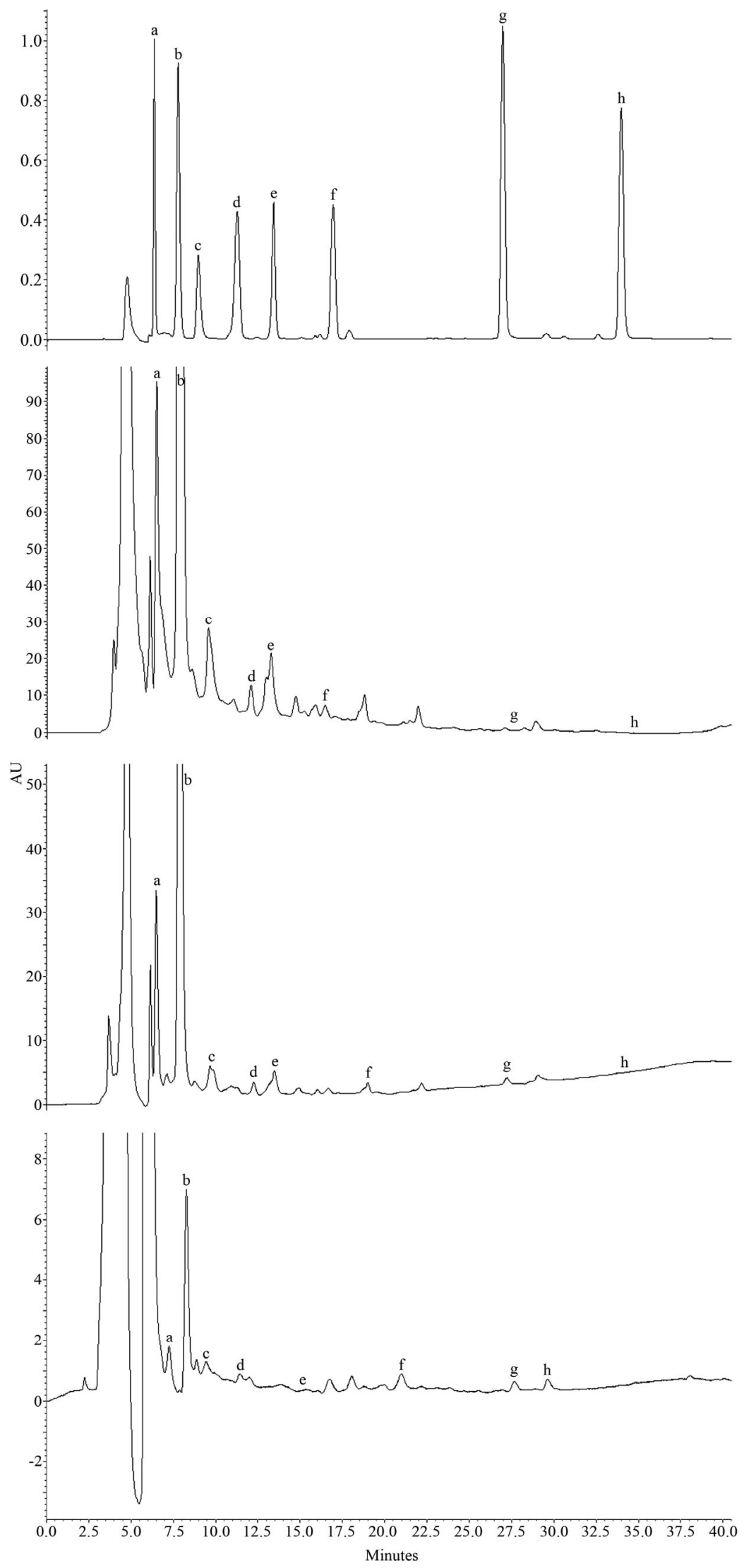

Figure 1. HPLC chromatogram of seed extract of selective genotypes of P. tetragonolobus at $254 \mathbf{n m}$. 


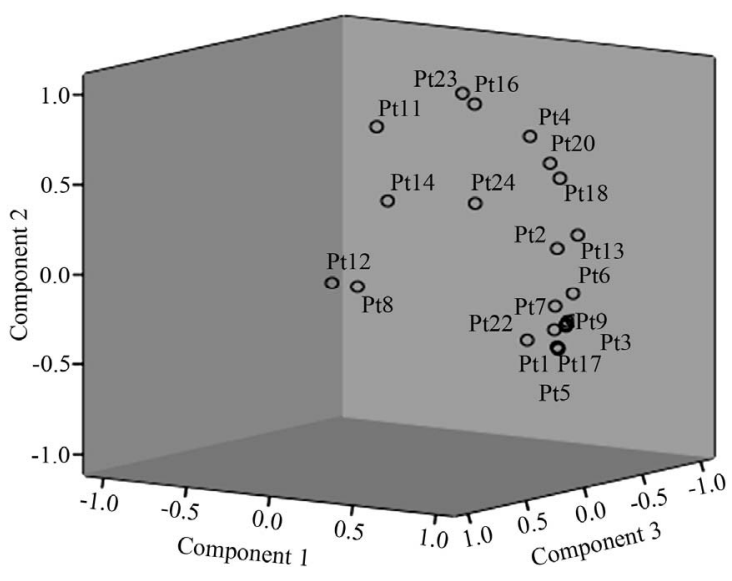

Figure 2. Principal component analysis (PCA) of polyphenol and flavonoid content of seeds in different genotypes of P. tetragonolobus.

total of 76 bands with an average of 5.8 bands per primer, out of which 52 bands were polymorphic with an average of 4 polymorphic bands per primer, revealing $68.4 \%$ polymorphism. Minimum number (01) of polymorphic band was amplified by primer OPM-14 and maximum number (08) of polymorphic bands was amplified by primer OPM-07. The PIC value ranged from 0.077 0.347 with an average value of 0.170 across the used primers (Table 2). Genetic distances among the genotypes ranged from 0.607 (between Pt4 and Pt15; Pt6 and Pt16) to 0.974 (between Pt09 and Pt17).

\subsection{ISSR Analysis}

A total of seven ISSR primers that resulted into distinct polymorphic bands were selected for ISSR profiling in the present study. Representative gel image for ISSR primer UBC 811 is shown in (Figure 3(b)). A total of 91 bands with an average of 13 bands per primer were obtained with seven ISSR markers. Primers UBC 810 and UBC 811 amplified the maximum number of bands (15), whereas primer UBC 840 amplified a minimum of 5 bands. Out of 91 bands, 86 bands were polymorphic revealing $94.5 \%$ polymorphism. Average number of polymorphic bands per primer was 12.2 with primer UBC 827 producing a maximum of 15 polymorphic bands, whereas primer UBC 840 producing a minimum of 5 polymorphic bands. The PIC value obtained ranged from $0.203-0.354$ with an average of 0.281 across all seven ISSR primers (Table 2). Genetic distances ranged from 0.250 (between Pt4 and Pt24 pair of genotypes) to 0.887 (between Pt10 and Pt11 pair of genotypes) across all 24 genotypes of winged bean.

\subsection{Cumulative Analysis Using RAPD and ISSR Markers}

Twenty RAPD and ISSR primers together amplified a

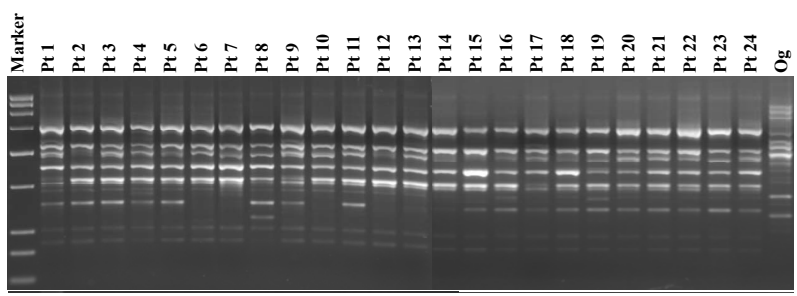

(a)

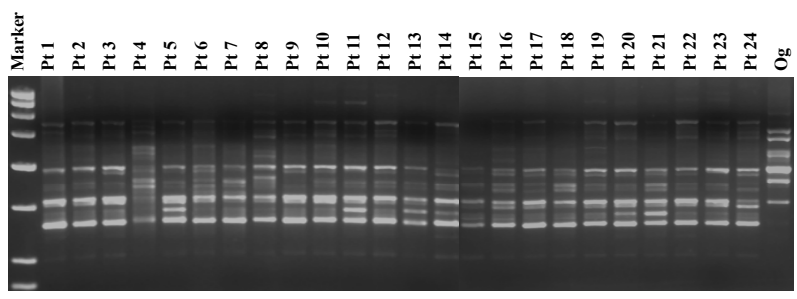

(b)

Figure 3. Representative gel images showing RAPD and ISSR-PCR profiles of Psophocarpus tetragonolobus genotypes using primers (a) OPH 4 and (b) UBC 811. Lanes indicated by marker contains Low range DNA ruler.

total of 167 bands, out of which 138 were polymorphic revealing $82.63 \%$ polymorphism across all winged bean genotypes. The average PIC value was 0.242 with twenty primers across all the genotypes (Table 3). Genetic distances varied from of 0.348 (between Pt6 and Pt16) to 0.883 (between Pt10 and Pt11) across different genotypes of winged bean.

\subsection{Comparison of Diversity Parameters Using RAPD and ISSR Markers}

Comparative study of different diversity parameters was made on the basis of two marker systems used in the present study. The average diversity index $\left(\mathrm{DI}_{\mathrm{a}}\right)$ value by ISSR was higher (0.299) than RAPD (0.261), similarly the marker index (MI) value in case of ISSR was higher (3.47) in comparison to RAPD (0.717) (Table 3). ISSR revealed higher polymorphism (94.5\%) than the RAPD (68.4\%), indicating that ISSR are more suitable and reliable than RAPD markers to unravel the genetic variability in winged bean genotypes. The correlation of genetic distances was performed between 1) RAPD vs. ISSR; 2) RAPD vs. cumulative; and 3) ISSR vs. cumulative. The matrix correlation value (r) between RAPD vs. ISSR was 0.83 , whereas it was 0.96 and 0.92 between RAPD vs. cumulative and ISSR vs. cumulative respectively (Table 4). These values revealed that RAPD vs. cumulative data have good correlation and are best fit to each other.

\subsection{Quantification of Phenolic Acids, Flavonols and Condensed Tannin}

Plant phenolic acids namely: gallic acid, protocatechuic acid, chlorogenic acid, caffeic acid, ferulic acid and fla- 
Table 3. Comparison of RAPD, ISSR and cumulative band data analyses in Psophocarpus tetragonolobus.

\begin{tabular}{cccc}
\hline Markers & RAPD & ISSR & *Cumulative \\
\hline No. of accessions & 24 & 24 & 24 \\
Total no of assays/primer & 13 & 07 & 20 \\
Band size range (bp) & $200-3000$ & $300-3000$ & $200-3000$ \\
Total no. of bands amplified \\
$\begin{array}{c}\text { (n) } \\
\text { Polymorphic bands (p) }\end{array}$ & 76 & 91 & 167 \\
$\begin{array}{c}\text { Polymorphism (\%) } \\
\text { Genetic distance range }\end{array}$ & $0.607-0.974$ & $0.250-0.8870 .348-0.883$ \\
$\quad \begin{array}{c}\text { Average PIC } \\
\text { Average Diversity Index } \\
\text { (DIav) }\end{array}$ & 0.170 & 0.281 & 0.242 \\
$\begin{array}{c}\text { Effective Multiplex ratio } \\
\text { (EMR) }\end{array}$ & 0.261 & 0.299 & 0.283 \\
$\begin{array}{c}\text { Marker Index (MI) } \\
\text { * }\end{array}$ & 0.717 & 11.61 & 6.07 \\
\hline
\end{tabular}

* combined data of RAPD and ISSR.

Table 4. Mantel correlation between the genetic distances obtained from RAPD, ISSR and cumulative data analyses in Psophocarpus tetragonolobus.

\begin{tabular}{ccc}
\hline Marker pairs & Correlation coefficient $(\boldsymbol{r})$ & $(\boldsymbol{p})$ value \\
\hline RAPD vs ISSR & 0.83935 & 0.0020 \\
RAPD vs * cumulative & 0.96996 & 0.0020 \\
ISSR vs * cumulative & 0.92355 & 0.0020 \\
\hline
\end{tabular}

"combined data of RAPD and ISSR.

vonols namely: rutin, quercitin and kaempferol were quantified from the dried powdered seeds of P. tetragonolobus through HPLC. The results were obtained by comparison with standards (Figure 1). The values obtained here are the mean values for three replicates of the same sample.Elution was carried out at a flow rate of 0.6 $\mathrm{ml} / \mathrm{min}$ with water: acetic acid $(99.0: 1.0 \mathrm{v} / \mathrm{v})$ as solvent A and acetonitrile as solvent $\mathrm{B}$ using a gradient elution in $0-14$ min with $20 \%-35 \%$ of solvent B, 14 - 40 min with $35 \%-50 \%$ of solvent B.

\subsection{Physiological Measurements of Light Response and Chlorophyll Fluorescence}

Light saturated maximum assimilation rate per unit leaf area $\left(A_{\text {sat }} ; \mu \mathrm{mol} \cdot \mathrm{m}^{-2} \cdot \mathrm{sec}^{-1}\right)$ during light response measurements (at PPFD of $1200 \mu \mathrm{mol} \cdot \mathrm{m}^{-2} \cdot \mathrm{sec}^{-1}$ ) was highest in P. tetragonolobus genotype Pt2 from India (20.72 \pm 1.41) while lowest assimilation rate was observed in genotype Pt16 from Thailand $(2.97 \pm 0.91)$ (Figure 4). The genotypes Pt13 (Nigeria), Pt4 (India), and Pt17

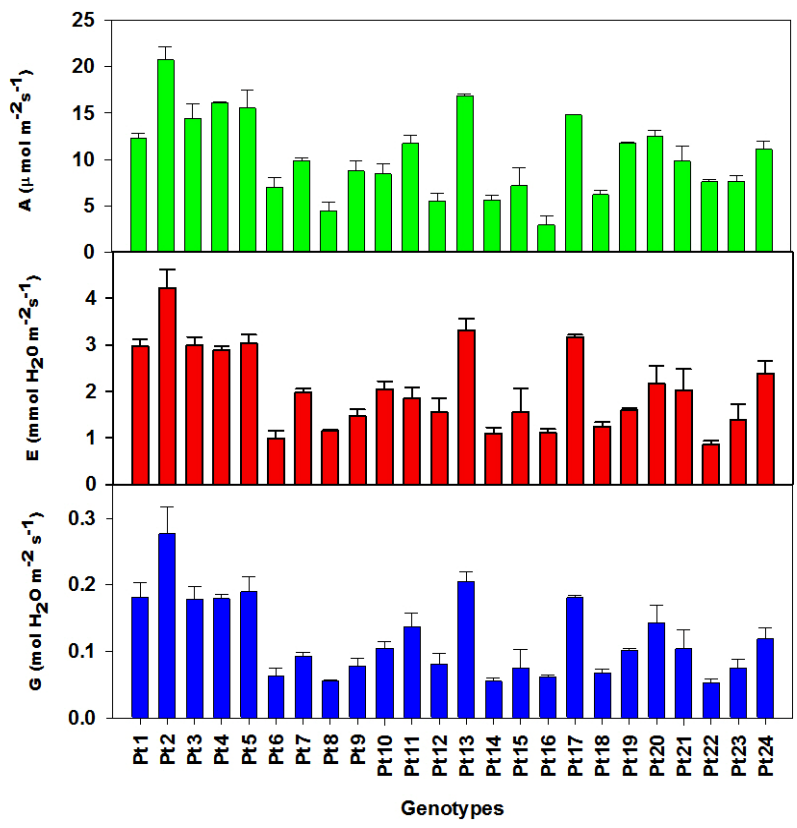

Figure 4. Vertical error bars of Photosynthesis (A; $\mu \mathrm{mol}$.

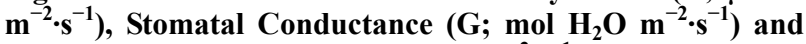
Leaf Transpiration $\left(\mathrm{E} ; \mathrm{mmol} \mathrm{H}_{2} \mathrm{O} \mathrm{m}^{-2} \cdot \mathrm{s}^{-1}\right.$ ) of 24 genotypes of P. tetragonolobus.

(Thailand) showed similar assimilation rates $(16.85 \pm$ $0.19,16.14 \pm 0.7$ and $14.78 \pm 0.01$, respectively). The genotypes Pt25 (Thailand), Pt1 (India) showed assimilation rate of $12.55 \pm 0.62$ and $12.31 \pm 0.48$ respectively, while the genotypes Pt19 (Thailand), Pt11, and Pt24 (Thailand) showed slightly lower assimilation rates $(11.78 \pm 0.06,11.71 \pm 0.93$ and $11.08 \pm 0.88$ respectively.) The Pt22 (Thailand) having an assimilation rate of $7.57 \pm 0.27 \mu \mathrm{mol} \cdot \mathrm{m}^{-2} \cdot \mathrm{sec}^{-1}$ had maximum instantaneous water use efficiency (WUE; $0.89 \pm 0.05$ ) (Figure 5) and showed minimum leaf transpiration $(\mathrm{E} ; 0.86 \pm 0.08$ mol $\mathrm{H}_{2} \mathrm{O} \mathrm{m} \mathrm{m}^{-2}$ ) (Figure 4). The photosynthetic yield $(0.08 \pm 0.001)$ and electron transport rate (ETR; $\mu \mathrm{mol}$ $\left.\mathrm{e}^{-} \mathrm{m}^{-2} \mathrm{sec}^{-1} ; 41.35 \pm 0.41\right)$ were also minimum in the genotype Pt16 (Thailand) whereas maximum yield (0.30 $\pm 0.001)$ and ETR $(156.57 \pm 0.57)$ was observed in genotype Pt2 (India) (Figure 6). Stomatal conductance was also maximum $(0.28 \pm 0.04)$ in genotype Pt2 (India) (Figure 4). Intercellular $\mathrm{CO}_{2}$ conc. $\left(\mathrm{Ci} ; \mu \mathrm{mol} \mathrm{CO} \mathrm{mol}^{-1}\right)$ values ranged between $158.13 \pm 12.73$ to $305.44 \pm 29.18$ among all genotypes (maximum in Pt2) (Figure 6). Maximum quantum yield of photosystem II ( Fv/Fm) measured after dark acclimation ranged from 0.77 (lowest) to 0.82 (highest) (Figure 5) whereas Fv'/Fm' (Light harvesting efficiency by oxidized PSII reaction centers in light) ranged from $0.46 \pm 0.01$ to $0.57 \pm 0.01$ among the global genotypes of winged bean (Figure 5).

\section{DISCUSSION}

The present study was intended to evaluate the level of 


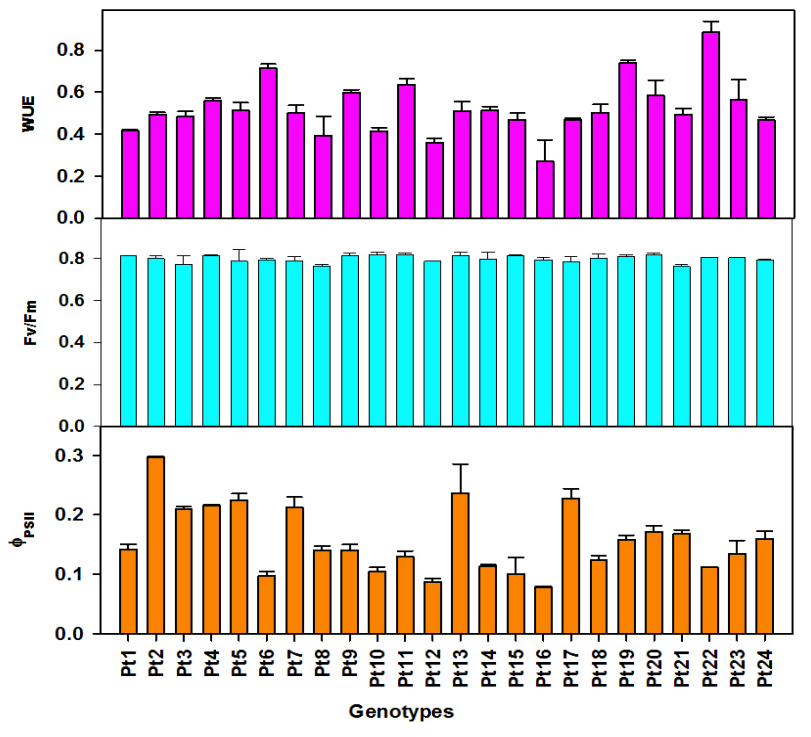

Figure 5. Vertical error bars of Water use efficiency (WUE), Fv/Fm (variable to maximal Fluorescence ratio (dark)) and ФPSII (Photosynthetic Quantum Yield of PSII) of 24 genotypes of $P$. tetragonolobus.

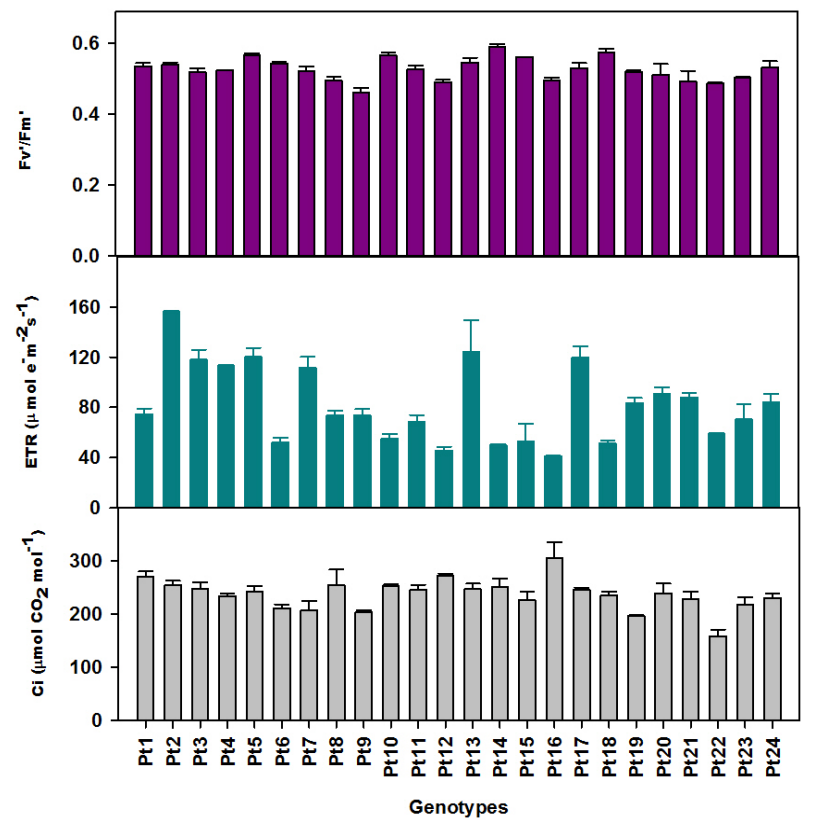

Figure 6. Vertical error bars of Fv'/Fm' (variable to maximal Fluorescence ratio (light)), ETR (Electron transport

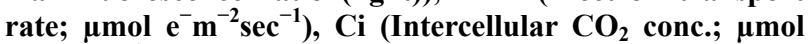
$\mathrm{CO}_{2} \mathrm{~mol}^{-1}$ ) of 24 genotypes of $P$. tetragonolobus.

genetic diversity and establish a genetic relationship across the winged bean genotypes with respect to specific polyphenol and flavonoid content and their response to various physiological conditions. The two DNA fingerprinting methods (RAPD and ISSR) were used in this study. Though differing in the underlying principle, were very informative with regard to the amount of polymorphism detected with each method. However, ISSR tech- nique was more efficient than RAPD in the present study to unravel polymorphism in winged bean genotypes. Utility and efficiency of ISSR markers over RAPD to unravel the genetic polymorphism have been proved in other legume crops such as chickpea [11], Arachis [27] etc. Nagaoka and Ogihara [28] have also reported that the ISSR primers produced several times more information than RAPD markers in wheat. The number of potential ISSR markers depends on the frequency of microsatellites, which changes with species and they are highly polymorphic and have been used in innumerable crop plants to study the genetic diversity, phylogeny, gene tagging, and genomic mapping [29]. In order to achieve a comprehensive genetic relationships, RAPD and ISSR band data were pooled together and analyzed to generate a cumulative UPGMA dendrogram, (Figure 7) thereby screening much larger portion of the genome to ensure its wider coverage and providing better reflection of the genetic relatedness and affinities of the winged bean genotypes in the present study. The UPGMA dendrogram grouped all the 24 genotypes into two major groups (A and $\mathrm{B}$ ). These groups were again categorized into 7 clusters. Cluster I consisted of four genotypes (Pt1, Pt2, Pt3 and Pt5) from India and two genotypes (Pt12 and Pt17) from Nigeria and Thailand and three genotypes (Pt9-Pt11) from unknown origin. Clusters II, III and IV clustered together all Thailand genotypes (Pt14-Pt24), except Pt17 which showed affinity to cluster I. Cluster V consisted of genotypes Pt 8 from India, showing affinity to Thailand genotypes. Genotypes Pt4 and Pt5 from India were grouped into Cluster VI whereas genotypes Pt6 separated out in Cluster VII with 100 percent bootstrap support. Furthermore, the out-group taxon clearly separated out from rest of the studied genotypes. Clustering pattern in UPGMA dendrogram revealed considerable genetic variations among winged bean genotypes and are indicative of the fact that the groupings were not in congruence with their geographical affiliations. Principal component analysis (PCA) performed on data matrices showed two major significant groups (Figure 2). In the grouping, Pt12 completely differs from other genotypes. Pt8, Pt11 and Pt14 also formed a separate stand in the groupings. The grouping of $\mathrm{Pt} 8$ as a different genotype is agreeable with the cumulative result of RAPD and ISSR.

The PCA analysis clearly separated tannin from the polyphenols and flavonoids but grouped closely with several other compounds like: rutin, ferulic acid and chlorogenic acid. As tannins are generally defined as naturally occurring polyphenolic compounds of high molecular weight $(500-3000 \mathrm{Da})$, which form complexes with proteins [30]. They are classified into two groups based on their structural type as hydrolysable tannins composed of a polyhydroxyl alcohol esterified with gallic or ellagic acid and the condensed tannins which are flavonoid-based polymers. Total phenolics and 


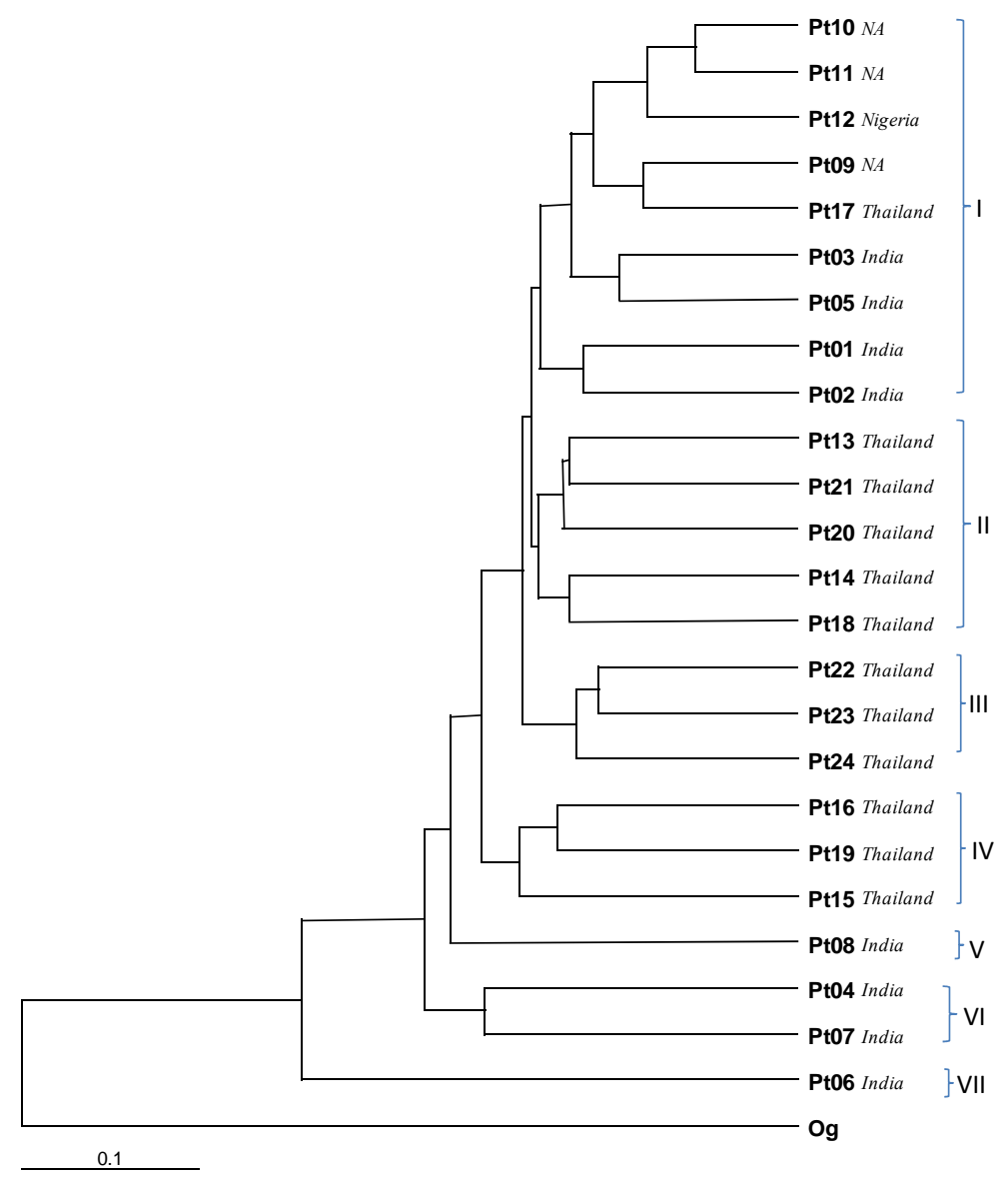

Figure 7. UPGMA dendrogram (generated for cumulative data of RAPD and ISSR) showing relationships of $P$. sophocarpus tetragonolobus gentotypes.

tannin compounds play an important role in human nutrition and the qualitative and quantitative data of these compounds may help in identification of seed genotypes with lower and higher content of polyphenols in the seed which may be further utilized for genetic improvement purposes. The range of total phenolics was between 0.09 to $3.49 \mu \mathrm{g} / \mathrm{g}$. The genotypes (Pt8 and Pt16) from Thailand showed highest 1.07 and $790.5 \mu \mathrm{g} / \mathrm{g}$ Kaempferol content in seeds.

Weighted clustering for plant performance upon three key physiological parameters especially photosynthesis rate $(\mathrm{A})$, photosynthetic yield $(\mathrm{Y})$ and stomatal conductance (Gs) were carried out among these 24 genotypes (Figures 4-6) of winged bean. The above cluster analysis showed two clusters (Figure 8). Cluster 1 again formed two sub-clusters $1 \mathrm{a}$ and $1 \mathrm{~b}$. Cluster $1 \mathrm{a}$ consisted of 5 genotypes (Pt8, Pt12, Pt14, Pt16 and Pt18) having lowest $\mathrm{CO}_{2}$ assimilation rate. Out of these 5 genotypes Pt14, Pt16 and Pt18 all from Thailand, showed close affinity to each other, while cluster $1 \mathrm{~b}$ clustered together 8 closely related genotypes (Pt6, Pt7, Pt9, Pt10 Pt15, Pt21, Pt22, Pt23). Cluster 2 consisted of two sub-cluster $2 \mathrm{a}$ and $2 \mathrm{~b}$. In cluster 2a genotypes Pt1, Pt3, Pt11, Pt17, Pt19, Pt25

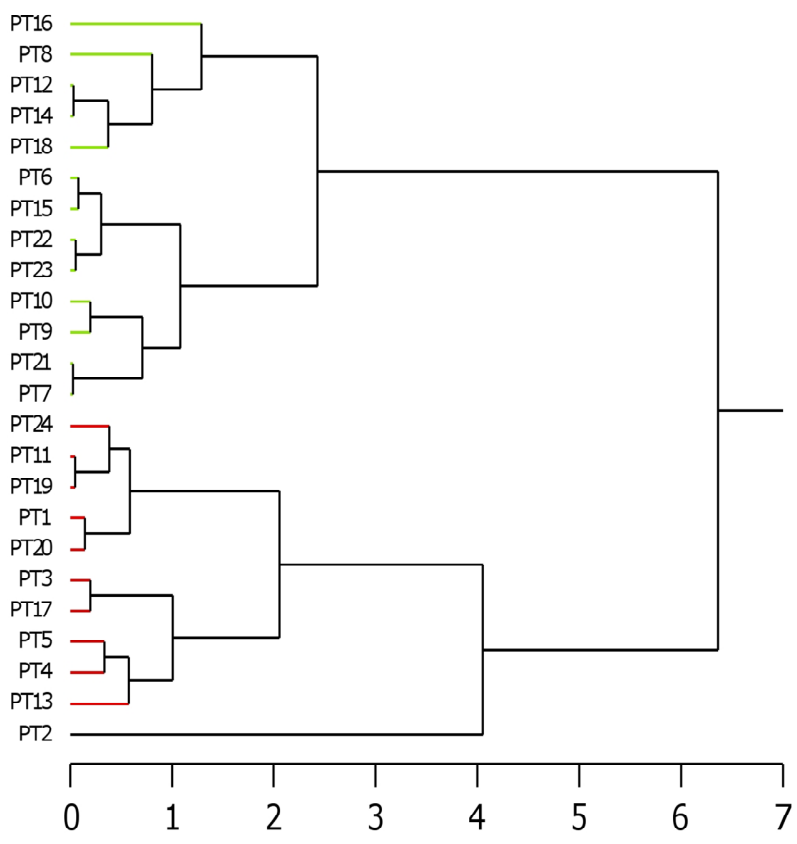

Figure 8. Cluster analysis (weighted) of photosynthesis, stomatal conductance and photosynthetic quantum yield among 24 genotypes of $P$. tetragonolobus. 
and Pt4, Pt5 showed close relationship whereas cluster $2 \mathrm{~b}$ had a single genotype (Pt2) showing maximum physiological performance with high transpiration rates, which is the most diverse among all the genotypes, whereas, the genotype Pt16 showed least physiological performance among all and occupied maximum cluster distance from the best performing genotype Pt2. There was little significant correlations between the physiological clustering patterns and those obtained by cumulative analysis of RAPD and ISSR data except for few genotypes (Pt22, Pt23) in which the inter cluster distance was least. The results obtained in the present study further suggested that physiological diversity in the genotypes of winged bean need not be necessarily related to genetic diversity.

\section{CONCLUSION}

The present study provided significant insights on the genetic diversity presenting in a global collection of winged bean genotypes and confirmed the potential use of RAPD and ISSR markers to unravel the extent of genetic variability. ISSR was found to be more efficient in comparison to RAPD markers revealing $94.5 \%$ polymorphism among the genotypes of winged bean. The level of genetic variability detected in this study could be further utilized in prospecting of highly diverse genotypes which could be of paramount significance for improving the food and nutrition quality of winged bean. The plants from Thailand have the highest content of polyphenols and tannin with hardiness towards improved physiological efficiency and transpiration rate. The information generated on the biochemical and physiological attributes of winged bean will certainly pave the ways for prospecting of this important underutilized food crop for its quality traits.

\section{ACKNOWLEDGEMENTS}

This work was supported under EMPOWER programme of Council of Scientific and Industrial Research (CSIR), Government of India and hence acknowledged. Due acknowledgment goes to N.B.P.G.R. for providing genotypes of winged bean seeds. Director CSIR-NBRI is duly acknowledged for providing basic infrastructure facilities to carry out this research work.

\section{REFERENCES}

[1] Peyachoknagul, S., Matsui, T., Shibata, H., Hara, S., Ikenaka, T., Okada, Y. and Ohno, T. (1989) Sequence and expression of the mRNA encoding the chymotrypsin inhibitor in winged bean (Psophocarpus tetragonolobus (L.) DC.). Plant Molecular Biology, 12, 51-58. http://dx.doi.org/10.1007/BF00017447

[2] Anon. (1981) The winged bean. A high-protein crop for the tropics. (2nd Edition) National Academy Press, Wa- shington DC, 46.

[3] Khan, T.N. (1982) Winged bean production in the tropics. FAO Plant Production and Protection Paper, 38, 222.

[4] Kortt, A.A. (1980) Isolation and properties of a chymotrypsin inhibitor from winged bean seed (Psophocarpus tetragonolobus (L) DC.). Biochimica et Biophysica acta (BBA)-Protein structure, 624, 237-248.

[5] Kantha, S.S., Hettiarachchy, N.S. and Erdman, J.W.Jr. (1986) Nutrient, antinutrient contents and solubility profiles of nitrogen, phytic acid and selected minerals in winged bean flour. Cereal Chemistry, 63, 9-13.

[6] Cabrera, A. and Martin, A. (1986) Variation in tannin content in Vicia faba L. Journal of Agricultural Science, 106, 377-382.

http://dx.doi.org/10.1017/S0021859600063978

[7] Sakiyama, N.S. (2000) DNA markers for coffee tree breeding. In: Sera, T., Soccol, C.R., Pandy, A. and Roussos S., Eds., Coffee Biotechnology and Quality, Kluwer Academic Publishers, Dordrecht, 179-185.

[8] Lazaroff, L. (1989) Strategy for development of a new crop. In: Wickens, G.E., Haq, N. and Day, P. Eds., New Crops for Food and Industry, Chapman and Hall, London, 108-119.

[9] Moussa, E.H., Millan, T., Gill, J. and Cubero, J.I. (1996) Variability and genome length estimation in chickpea (Cicer arietinum L.) revealed by RAPD analysis. Journal of Genetics \& Breeding, 51, 83-85.

[10] Sant, V.J., Patankar, A.G., Sarode, N.D., Mhase, L.B., Sainani, M.N., Deshmukh, R.B., Ranjekar, P.K. and Gupta, V.S. (1999) Potential of DNA markers in detecting divergence and in analyzing heterosis in Indian elite chickpea cultivars. Theoretical and Applied Genetics, 98, 1217-1225.

[11] Collard, B.C.Y., Pang, E.C.K. and Taylor, P.W.J. (2003) Selection of wild Cicer accessions for the generation of mapping populations segregating for resistance to Ascochyta blight. Euphytica, 130, 1-9. http://dx.doi.org/10.1023/A:1022316328843

[12] Duran, Y., Fratini, R., Garcia, P. and Perez de la, V.M. (2004) An inter-subspecific genetic map of Lens. Theoretical and Applied Genetics, 108, 1265-1270. http://dx.doi.org/10.1007/s00122-003-1542-3

[13] Edossa, F., Kassahun, T. and Endashaw, B. (2007) Genetic diversity and population structure of Ethiopian lentil (Lens culinaris Medikus) landraces as revealed by ISSR marker. African Journal of Biotechnology, 6, 1460-1468.

[14] Suvendu, M., Sutar, A.M. and Badigannavar, A.M. (2009) Assessment of Genetic diversity in cultivated groundnut (Arachis hypogaea L.) with differential responses to rust and late leaf spot using ISSR markers. Indian Journal of Genetics, 69, 219-224.

[15] Malviya, N. and Yadav, D. (2010) RAPD analysis among pigeon pea [Cajanus cajan (L.) Mill sp.] cultivars for their genetic diversity. Biomedical \& Life Sciences, 3, 322-330.

[16] Pathak, R., Singh, S.K., Singh, M. and Henry, A. (2010) Molecular assessment of genetic diversity in cluster bean (Cyamopsis tetragonoloba) genotypes. Journal of Genet- 
ics, 89, 243-246.

[17] Tantasawat, P., Trongchuen, J., Prajongjai, T., Thongpae, T., Petkhum, C., Seehalak, W. and Machikowa, T. (2010) Variety identification and genetic relationships of mungbean and blackgram in Thailand based on morphological characters and ISSR analysis. African Journal of Biotechnology, 9, 4452- 4464.

[18] Khan, MA., Von, Witzke-Ehbrecht S., Maass, BL. and Becker, HC., (2009) Relationships among different geographical groups, agro-morphology, fatty acid composition and RAPD marker diversity in safflower (Carthamus tinctorius). Genetic Resources and Crop Evolution, 56, 19-30. http://dx.doi.org/10.1007/s10722-008-9338-6

[19] Basha, S.D., Francis, G., Makkar, H.S.P., Becker, K. and Sujatha, M. (2009) A comparative study of biochemical traits and molecular markers for assessment of genetic relationships between Jatropha curcas L. germplasm from different countries. Plant Science, 176, 812-823. http://dx.doi.org/10.1016/j.plantsci.2009.03.008

[20] Jaccard, P. (1908) Nouvelles rechers fur la distribution florale. Bulletin de la Société Vaudoise des Sciences Naturelles, 44, 223-270.

[21] Pavlicek, A., Hrda, S. and Flegr, J. (1999) Free tree free ware program for construction of phylogenetic trees on the basis of distance data and bootstrap/Jack Knife analysis of the tree robustness.Application in the RAPD analysis of genus Frenkelia. Folia Biologica, 45, 97-99.

[22] Powell, W., Morgante, M., Andre, C., Hanafey, M., Vogel, J., Tingey, S. and Rafalski, A. (1996) The comparison of RFLP, RAPD, AFLP and SSRP (microsatellite) markers for germplasm analysis. Molecular Breeding, 2, 225-238. http://dx.doi.org/10.1007/BF00564200

[23] Mantel, N. (1967) The detection of disease clustering and a generalized regression approach. Cancer Research, 27, 209-220.

[24] Rohlf, F.J. (2000) NTSYS-pc: Numerical taxonomy and multivariate analysis system, version 2.1. Exeter Software Setauket, New York.

[25] Ragazzi, E. and Veronese, G. (1973) Quantitative analysis of phenolics compounds after thin-layer chromatographic separation. Journal of Chromatography, 77, 369375. http://dx.doi.org/10.1016/S0021-9673(00)92204-0

[26] Niranjan, A., Barthwal, J., Govindrajan, R., Singh, DP., Lehri, A. and Amla, DV. (2009) Development and validation of HPLC-UV-MS/MS method for identification and quantification of polyphenols in Artemisia pallens L. Acta Chromatographica, 21,105-116. http://dx.doi.org/10.1556/AChrom.21.2009.1.9

[27] Raina, S.N., Rani, V., Kojima, T., Ogihara, Y., Singh, K.P. and Devarumath, R.M. (2001) RAPD and ISSR fingerprints as useful genetic markers for analysis of genetic diversity, varietal identification, and phylogenetic relationships in peanut (Arachis hypogaea) cultivars and wild species. Genome, 44, 763-772.

[28] Nagaoka,T., and Ogihara, Y. (1997) Applicability of inter simple sequence repeat polymorphisms in wheat for use as DNA markers in comparison to RFLP and RAPD markers. Theoretical and Applied Genetics, 94, 597-602. http://dx.doi.org/10.1007/s001220050456

[29] Reddy, M.P., Sarla, N. and Siddiq, E.A. (2002) Inter simple sequence repeat (ISSR) polymorphism and its application in plant breeding. Euphytica, 128, 9-17. http://dx.doi.org/10.1023/A:1020691618797

[30] Hagerman, A.E., Rice, M.E. and Ritchard, N.T. (1998) Mechanisms of protein precipitation for two tannins, pentagalloyl glucose and epicatechin $\operatorname{lo}_{16}(4 \rightarrow 8)$ catechin (Procyanidin). Journal of Agricultural and Food Chemistry, 46, 2590-2595. http://dx.doi.org/10.1021/jf971097k 